\title{
High Thyrotropin Is Critical for Cardiac Electrical Remodeling and Arrhythmia Vulnerability in Hypothyroidism
}

\author{
Julieta Fernandez-Ruocco, ${ }^{1,2, *}$ Monica Gallego, ${ }^{3, *}$ Ainhoa Rodriguez-de-Yurre, ${ }^{1,3}$ Julian Zayas-Arrabal, ${ }^{3}$ \\ Leyre Echeazarra, ${ }^{3}$ Amaia Alquiza, ${ }^{3}$ Victor Fernández-López, ${ }^{3}$ Juan M. Rodriguez-Robledo, ${ }^{3}$ \\ Oscar Brito, ${ }^{4}$ Ygor Schleier, ${ }^{1}$ Marisa Sepulveda, ${ }^{2}$ Natalia F. Oshiyama, ${ }^{5}$ Martin Vila-Petroff, ${ }^{2}$ \\ Rosana A. Bassani, ${ }^{5}$ Emiliano H. Medei, ${ }^{1}$ and Oscar Casis ${ }^{3}$
}

Background: Hypothyroidism, the most common endocrine disease, induces cardiac electrical remodeling that creates a substrate for ventricular arrhythmias. Recent studies report that high thyrotropin (TSH) levels are related to cardiac electrical abnormalities and increased mortality rates. The aim of the present work was to investigate the direct effects of TSH on the heart and its possible causative role in the increased incidence of arrhythmia in hypothyroidism.

Methods: A new rat model of central hypothyroidism (low TSH levels) was created and characterized together with the classical propylthiouracil-induced primary hypothyroidism model (high TSH levels). Electrocardiograms were recorded in vivo, and ionic currents were recorded from isolated ventricular myocytes in vitro by the patch-clamp technique. Protein and mRNA were measured by Western blot and quantitative reverse transcription polymerase chain reaction in rat and human cardiac myocytes. Adult human action potentials were simulated in silico to incorporate the experimentally observed changes.

Results: Both primary and central hypothyroidism models increased the L-type $\mathrm{Ca}^{2+}$ current $\left(\mathrm{I}_{\mathrm{Ca}-\mathrm{L}}\right)$ and decreased the ultra-rapid delayed rectifier $\mathrm{K}^{+}$current $\left(\mathrm{I}_{\mathrm{Kur}}\right.$ ) densities. However, only primary but not central hypothyroidism showed electrocardiographic repolarization abnormalities and increased ventricular arrhythmia incidence during caffeine/dobutamine challenge. These changes were paralleled by a decrease in the density of the transient outward $\mathrm{K}^{+}$current $\left(\mathrm{I}_{\mathrm{to}}\right)$ in cardiomyocytes from animals with primary but not central hypothyroidism. In vitro treatment with TSH for 24 hours enhanced isoproterenol-induced spontaneous activity in control ventricular cells and diminished $\mathrm{I}_{\text {to }}$ density in cardiomyocytes from control and central but not primary hypothyroidism animals. In human myocytes, TSH decreased the expression of KCND3 and KCNQ1, $\mathrm{I}_{\mathrm{to}}$, and the delayed rectifier $\mathrm{K}^{+}$current $\left(\mathrm{I}_{\mathrm{Ks}}\right)$ encoding proteins in a protein kinase A-dependent way. Transposing the changes produced by hypothyroidism and TSH to a computer model of human ventricular action potential resulted in enhanced occurrence of early afterdepolarizations and arrhythmia mostly in primary hypothyroidism, especially under $\beta$-adrenergic stimulation.

Conclusions: The results suggest that suppression of repolarizing $\mathrm{K}^{+}$currents by TSH underlies most of the electrical remodeling observed in hypothyroidism. This work demonstrates that the activation of the TSHreceptor/protein kinase A pathway in the heart is responsible for the cardiac electrical remodeling and arrhythmia generation seen in hypothyroidism.

Keywords: ionic currents, cardiac electrophysiology, repolarization, cardiomyocyte, thyroid

\footnotetext{
${ }^{1}$ Instituto de Biofísica Carlos Chagas Filho, Universidade Federal do Rio de Janeiro, Rio de Janerio, Brazil.

${ }^{2}$ Centro de Investigaciones Cardiovasculares, Conicet La Plata, Facultad de Ciencias Médicas, Universidad Nacional de La Plata, Buenos Aires, Argentina.

${ }^{3}$ Departamento de Fisiología, Facultad de Farmacia, Universidad del País Vasco UPV/EHU, Vitoria, Spain.

${ }^{4}$ National Institute of Cardiology (INC), Rio de Janeiro, Brazil.

${ }^{5}$ Center for Biomedical Engineering, University of Campinas, Campinas, Brazil.

*These authors contributed equally in this work.

(C) Julieta Fernandez-Ruocco et al. 2019; Published by Mary Ann Liebert, Inc. This Open Access article is distributed under the terms of the Creative Commons License (http://creativecommons.org/licenses/by/4.0), which permits unrestricted use, distribution, and reproduction in any medium, provided the original work is properly cited.
} 


\section{Introduction}

$\mathbf{R}$ ECENT STUDIES HIGHLIGHT the importance of thyrotropin (TSH) levels in the mortality of both hypothyroid and euthyroid individuals. Patients with treated overt hypothyroidism with serum TSH levels between 0.5 and $5 \mathrm{mIU} / \mathrm{L}$ have significantly lower mortality rates than patients with TSH levels between 5 and $10 \mathrm{mIU} / \mathrm{L}$ (1). Moreover, a recent study demonstrated that high-normal TSH levels are associated with higher mortality than mid-normal levels in nonhypothyroid individuals (2), but the mechanisms responsible for this elevated mortality are unknown.

In this context, it has been reported that hypothyroid patients show electrocardiogram (ECG) abnormalities such as atrial fibrillation, prolonged QT and QTc intervals, and greater QT dispersion. This electrical remodeling creates a pro-arrhythmic substrate and facilitates the occurrence of ventricular arrhythmias including torsades de pointes (3-7). Surprisingly, patients with subclinical hypothyroidism, with normal triiodothyronine (T3)/thyroxine (T4) levels but elevated TSH, show similar repolarization alterations in the ECG as those with overt hypothyroidism $(5,7)$, suggesting the involvement of TSH in cardiac electrical remodeling and arrhythmia. In the last decade, clinical observations have shown a direct correlation between serum TSH levels and QT/QTc prolongation in hypothyroid patients (4,5,7-9). In agreement with this hypothesis, it was recently reported that in vitro treatment of healthy cardiac myocytes with TSH decreases the amplitude of different repolarizing $\mathrm{K}^{+}$currents and the expression of their channel proteins (10).

This study used animal models of primary (high TSH) and central (low TSH) hypothyroidism, as well as adult human atrial myocytes and computational modeling, to gain insight into the mechanisms underlying myocardial electrical remodeling by TSH. The results presented here suggest that the cardiac electrical remodeling and enhanced arrhythmia susceptibility in primary hypothyroidism under adrenergic stimulation are due to: (i) an increase of the depolarizing inward calcium current secondary to the reduction of thyroid hormone levels; (ii) a TSH receptor/protein kinase A (PKA)-dependent reduction of the expression of the pore-forming proteins of the channels that carry the repolarizing outward potassium currents $\mathrm{I}_{\text {to }}$ and $\mathrm{I}_{\mathrm{Ks}}$; and (iii) the appearance of early afterdepolarizations (EAD) and arrhythmias secondary to prolongation of repolarization, especially under $\beta$-adrenergic stimulation. In summary, this work demonstrates the direct involvement of TSH in the cardiac electrical remodeling and arrhythmia predisposition seen in hypothyroidism.

\section{Methods}

\section{Animals and induction of hypothyroidism}

The investigation fulfilled the Spanish (RD 1201/2005), Brazilian (Federal Law 11794), and European (D2003/65/CE and R2007/526/CE) rules for animal care used for experimental and other research purposes, and has been approved by the Ethics Committee for Animal Care of the Universidad del País Vasco (CEBA/46/2010) and the Ethics Committee for Animal Care and Use of the University of Campinas (CEUA/B/UNICAMP, Brazil, No. 4429-1).

Hypothyroidism was induced in Sprague Dawley rats (200 g). Primary hypothyroidism was induced by the addition of $0.02 \%$ propylthiouracil (PTU; Sigma-Aldrich) to the drinking water for six weeks, which is a widely used, well characterized animal model of primary hypothyroidism. For induction of central hypothyroidism, animals were treated by daily gavage with bexarotene (BXT) for six weeks at a dose of $50 \mathrm{mg} / \mathrm{kg}$, which was the lowest tested dose that induced hypothyroidism in $100 \%$ of the animals in preliminary experiments. Previous tests also showed an absence of differences between rats receiving daily gavage with dimethyl sulfoxide, which was used to dissolve BXT, and non-treated controls.

Animals were weighed weekly, and body temperature was taken as that measured from the outer ear with an infrared thermometer. Blood samples were collected from the tail vein under light anesthesia (with isofluorane), and hormone levels were determined with T4 and TSH enzyme-linked immunosorbent assay kits (Diametra and Demeditec Diagnosis Gmbh, respectively) following the manufacturers' instructions. After six weeks, the animals were killed by heart removal under deep anesthesia with ketamine and xylazine $(50 \mathrm{mg} / \mathrm{kg}$ and $1.5 \mathrm{mg} / \mathrm{kg}$, respectively, administered intraperitoneally [i.p.]). The thyroid glands were removed and immersed in $4 \%$ paraformaldehyde. After fixation, $30 \mu \mathrm{m}$ sections were stained with hematoxylin and eosin.

\section{In vivo electrophysiological experiments}

ECG recording was carried out in conscious animals with permanent surgical steel electrodes inserted under anesthesia, positioned in the DII lead, and connected by flexible cables to a differential amplifier MP35 (Biopac Systems, Inc.). The signal was filtered at $100 \mathrm{~Hz}$ and digitized at $1 \mathrm{kHz}$ using BSL Pro v3.7 (Biopac Systems, Inc.). The measurements were performed blinded to the experimental groups. The QT interval was measured from the beginning of the QRS complex to the end of the $\mathrm{T}$ wave and was corrected for the heart rate using the Bazzet formula, QTc $=\mathrm{QT} / \sqrt{ } \mathrm{R}-\mathrm{R}$.

At the end of the six-week experimental period, the arrhythmia vulnerability test was performed in control and hypothyroid rats under isoflurane anesthesia. A baseline ECG was recorded for three minutes, and then rats were injected with caffeine $(120 \mathrm{mg} / \mathrm{kg}$ i.p.) and dobutamine $(50 \mu \mathrm{g} / \mathrm{kg}$ administered intravenously). The ECG was then recorded for 10 minutes, and the incidence of arrhythmias was quantified.

\section{Ventricular myocyte isolation}

Cardiac myocytes were isolated in a Langendorff apparatus, as previously described $(10,11)$. The hearts were mounted through the aorta on a Langendorff apparatus and perfused retrogradely with Tyrode solution containing (in mmol/L): $\mathrm{NaCl} 118, \mathrm{KCl} 5.4, \mathrm{NaHCO}_{3} 24, \mathrm{MgCl}_{2} 1.02$, $\mathrm{CaCl}_{2}$ 1.8, $\mathrm{NaH}_{2} \mathrm{PO}_{4}$ 0.42, dextrose 12, and taurine 20, bubbled with $95 \% \mathrm{O}_{2}$ and $5 \% \mathrm{CO}_{2}, \mathrm{pH} 7.4$, at $37^{\circ} \mathrm{C}$, followed by perfusion with the same solution without $\mathrm{Ca}^{2+}$ to which collagenase type II $(0.5 \mathrm{mg} / \mathrm{mL})$ and protease type XIV $(0.03 \mathrm{mg} / \mathrm{mL})$ were added later. Hearts were finally perfused with $\mathrm{KB}$ solution (in mmol/L): taurine 10 , glutamic acid 70 , creatine 0.5 , succinic acid 5 , dextrose $10, \mathrm{KH}_{2} \mathrm{PO}_{4} 10, \mathrm{KCl}$ 20, HEPES $^{-} \mathrm{K}^{+} 10, \mathrm{EGTA}^{-} \mathrm{K}^{+} 0.2, \mathrm{pH}$ adjusted to 7.4 with $\mathrm{KOH}$. Then, the ventricular cardiomyocytes were dissociated by mechanical agitation. When isolated for cardiac calcium 
handling experiments, EGTA was not included in the KB solution.

\section{In vitro electrophysiology patch-clamp experiments}

All experiments were performed at room temperature (20$22^{\circ} \mathrm{C}$ ). Following the patch rupture, the whole-cell membrane capacitance was measured by integration of the capacitive transients elicited by voltage steps from -50 to $-60 \mathrm{mV}$. Series resistance was compensated $80 \%$ in order to minimize voltage errors.

Ionic currents were recorded using the whole-cell configuration with an Axopatch 200B patch-clamp amplifier (Molecular Devices). Recording pipettes pulled from borosilicate tubes (Sutter Instruments) had a tip resistance of 1-3 $\mathrm{M} \Omega$ when filled with the internal solution. The pipette solution used for $\mathrm{I}_{\text {to }}$ and $\mathrm{I}_{\mathrm{Ca}-\mathrm{L}}$ recording was (in $\mathrm{mmol} / \mathrm{L}$ ): $\mathrm{L}$ aspartic acid (potassium salt) $80, \mathrm{KH}_{2} \mathrm{PO}_{4} 10, \mathrm{MgSO}_{4} 1, \mathrm{KCl}$ 50, HEPES $^{-} \mathrm{K}^{+} 5, \mathrm{ATP}^{-} \mathrm{Na}_{2} 3, \mathrm{EGTA}^{-} \mathrm{K}^{+} 10, \mathrm{pH}$ adjusted to 7.2 with $\mathrm{KOH}$. For the current carried by $\mathrm{NCX}\left(\mathrm{I}_{\mathrm{NCX}}\right)$, the internal solution was: $\mathrm{CsCl} 115, \mathrm{NaCl} 10$, TEA-Cl 10, MgATP $5, \mathrm{MgCl}_{2}$ 0.5, HEPES 10, $\mathrm{pH}$ adjusted to 7.2 with $\mathrm{CsOH}$.

For $\mathrm{I}_{\mathrm{to}}$ recording, the bath solution was (in $\mathrm{mmol} / \mathrm{L}$ ): $\mathrm{NaCl}$ 86, $\mathrm{MgCl}_{2} 1, \mathrm{HEPES}^{-} \mathrm{Na}^{+} 10, \mathrm{KCl} 4, \mathrm{CaCl}_{2} 0.5, \mathrm{CoCl}_{2} 2$, dextrose 11, TEA-Cl 50, pH adjusted to 7.4 with $\mathrm{NaOH}$. For $\mathrm{I}_{\mathrm{Ca}}-\mathrm{L}$, the solution composition was (in mmol/L): $\mathrm{NaCl} 86$, $\mathrm{MgCl}_{2} 1, \mathrm{HEPES} \mathrm{Na}^{+} 10, \mathrm{KCl} 4, \mathrm{CaCl}_{2} 1.8$, TEA-Cl 50, 4aminoprirydine 4 , dextrose $11, \mathrm{pH}$ adjusted to 7.4 with $\mathrm{NaOH}$. Voltage pulses $(500 \mathrm{~ms}$ long) to a test potential ranging from -30 to $+50 \mathrm{mV}$, starting from a holding potential of $-60 \mathrm{mV}$, were applied at a frequency of $0.1 \mathrm{~Hz}$ to ensure the full channel recovery from inactivation, whereas for $\mathrm{I}_{\mathrm{Ca}}-\mathrm{L}$ recording, the $500 \mathrm{~ms}$ test pulses were preceded by a $40 \mathrm{~ms}$ pre-pulse to $-40 \mathrm{mV}$.

For recording $\mathrm{I}_{\mathrm{NCX}}$, the external solution was (in $\mathrm{mmol} / \mathrm{L}$ ): $\mathrm{CsCl} 10, \mathrm{NaCl} 130, \mathrm{MgCl}_{2} 0.5, \mathrm{CaCl}_{2}$ 1, HEPES 10, dextrose $10, \mathrm{pH}$ adjusted to 7.4 with $\mathrm{NaOH}$. The current was recorded during application of a ramp from +80 to $-140 \mathrm{mV}$ following a $150 \mathrm{~ms}$ step to $+80 \mathrm{mV}$, from a holding potential of $-90 \mathrm{mV}$, after sequential pre-pulses to -45 and $0 \mathrm{mV}$ to inactivate $\mathrm{Na}^{+}$ and $\mathrm{Ca}^{2+}$ channels, respectively. The protocol was repeated in the presence of $10 \mathrm{mM} \mathrm{NiCl} 2$ to inhibit $\mathrm{NCX}$. $\mathrm{I}_{\mathrm{NCX}}$ was considered as the difference of the currents recorded in the absence and presence of $\mathrm{Ni}^{2+}$.

The voltage-clamp experimental protocols were controlled with the "Clampex" program, and current recordings were analyzed with the "Clampfit" program of the pClamp10.2 software (Molecular Devices). Current amplitudes were normalized to cell capacitance and expressed as $\mathrm{pA} / \mathrm{pF}$.

\section{Measurement of $\left[\mathrm{Ca}^{2+}\right]_{i}$}

After 24 hours of incubation at $4^{\circ} \mathrm{C}$ with EGTA-free $\mathrm{KB}$ solution with or without $30 \mathrm{mIU} / \mathrm{L} \mathrm{TSH},\left[\mathrm{Ca}^{2+}\right]_{\mathrm{i}}$ was measured in rat myocytes loaded with indo-1 AM (Molecular Probes) for 15 minutes followed by 30 minutes of washout. Cells were perfused at $22-24^{\circ} \mathrm{C}$ with Tyrode's solution containing $1 \mathrm{mmol} / \mathrm{L} \mathrm{CaCl}_{2}$. The fluorescence emission ratio at 410 and $485 \mathrm{~nm}$ under $360 \mathrm{~nm}$ excitation was converted to $\left[\mathrm{Ca}^{2+}\right]_{\mathrm{I}}$, as described elsewhere (11). $\mathrm{Ca}^{2+}$ transients were recorded after interruption of $1 \mathrm{~Hz}$ electrical stimulation followed by switching perfusion to normal or $\mathrm{Na}^{+}, \mathrm{Ca}^{2+}$-free Tyrode solution containing $10 \mathrm{mmol} / \mathrm{L}$ caffeine. The rate constant of $\left[\mathrm{Ca}^{2+}\right]_{\mathrm{i}}$ decline $(\mathrm{K})$ was determined by nonlinear curve fit. Sustained activation of sarcoplasmic reticulum (SR) $\mathrm{Ca}^{2+}$ release channels by caffeine prevents net $\mathrm{Ca}^{2+}$ accumulation in the organelle, so that most of $\left[\mathrm{Ca}^{2+}\right]_{i}$ decline should be carried by the NCX, if the external solution contains $\mathrm{Na}^{+}$, whereas the exchanger is thermodynamically inhibited in $\mathrm{Na}^{+}$-free medium. Thus, the ratio of $\mathrm{K}$ determined in the presence and absence of extracellular $\mathrm{Na}^{+}$can be used as an index of the NCX activity in the $\mathrm{Ca}^{2+}$ efflux mode (12).

The effect of $\beta$-adrenergic stimulation at inducing spontaneous activity was assessed by determination of concentration-effect curves to isoproterenol (ISO), in which the rate of spontaneous $\mathrm{Ca}^{2+}$ transients was measured after interruption of electrical stimulation.

\section{Quantitative real-time polymerase chain reaction}

This study conforms to the principles outlined in the Declaration of Helsinki and was approved by the Ethics Committee of the Instituto Nacional de Cardiologia (CEP-0358/ 07-11-2011). Human right atrial samples were obtained from patients in sinus rhythm who underwent cardiac surgery $(n=8)$. Clinical data of the patients are included in Supplementary Table S1.

Just after excision, each sample was cut in pieces that were incubated for 24 hours at $4^{\circ} \mathrm{C}$ in the absence or in the presence of $\mathrm{TSH}$, either with or without of $5 \mu \mathrm{mol} / \mathrm{L}$ of the PKA blocker $\mathrm{H} 89$, after which the levels of mRNA expression of the $K C N D 3$, $K C N Q 1$, and $K C N H 2$ genes were measured by quantitative reverse transcription polymerase chain reaction. Total RNA was extracted from $10 \mathrm{mg}$ of frozen tissue treated with DNase using the RNeasy ${ }^{\circledR}$ Fibrous Tissue Mini Kit (Qiagen) following the manufacturer's instructions. The concentration of total RNA in each sample was measured spectrophotometrically using NanoDrop 2000 (Thermo Fisher Scientific). Next, $1 \mu \mathrm{g}$ of total RNA was reversely transcribed into cDNA using random primers and the High Capacity Reverse Transcription Kit (Applied Biosystems). The reactions were carried out in the PTC-100 Programmable Thermal Controller (MJ Research). The program was $25^{\circ} \mathrm{C}$ for 10 minutes, $37^{\circ} \mathrm{C}$ for 120 minutes, $85^{\circ} \mathrm{C}$ for 5 minutes, and $4^{\circ} \mathrm{C}$ for 10 minutes.

Determinations were performed on 96-well plates in $15 \mu \mathrm{L}$ final volume containing $2 \mu \mathrm{L}$ of $10 \times$ diluted $K C N D 3$, $K C N H 2$, and $K C N Q 1$ cDNA stock, $7.5 \mu \mathrm{L}$ of Power SYBR Master Mix (Applied Biosystems), and $150 \mathrm{mmol} / \mathrm{L}$ of each forward and reverse of $K C N D 3, K C N H 2$, and $K C N Q 1$ primers (see Supplementary Table S2). The amplification program was $55^{\circ} \mathrm{C}$ for 2 minutes, $95^{\circ} \mathrm{C}$ for 10 minutes, followed by 40 cycles of $95^{\circ} \mathrm{C}$ for 30 seconds and $60^{\circ} \mathrm{C}$ for 1 minute. Each cDNA in duplicate and a corresponding sample without reverse transcriptase were included as a negative control. The mRNA expression of the chosen genes was normalized to that of GAPDH used as an internal control. The relative quantities of gene-specific mRNA were determined by the comparative $\mathrm{Ct}$ method, by which the relative gene expression in the TSH-treated group is expressed by the formula $2^{(\Delta \Delta \mathrm{Ct})}$, where $\mathrm{Ct}$ refers to the "threshold cycle", determined for each plate by the ViiA ${ }^{\mathrm{TM}} 7$ Real-Time PCR System (Applied Biosystems); $\Delta \mathrm{Ct}$ is the difference between the $\mathrm{Ct}$ values of the target mRNA and that of GAPDH; and $\Delta \Delta \mathrm{Ct}$ is the difference between the mean $\Delta \mathrm{Ct}$ of the TSH and control groups. The fold-change in the expression of the 
target genes was calculated as the mean \pm standard deviation of $2^{(\Delta \Delta \mathrm{Ct})}$ for the control and TSH groups.

\section{Computational modeling}

Human ventricular action potentials (AP) of 550 control individuals in resting conditions and under $\beta$-adrenergic stimulation were simulated using the O'Hara-Rudy dynamic (ORd) model (13) as baseline. Following the methodology by Passini et al. (14), ionic conductances were set at 20-200\% of the baseline values of the ORd "average human" to include ion current profiles with variable channel densities while keeping the AP parameters (peak voltage, maximum upstroke velocity, resting membrane potential, AP duration at $50 \%$ and $90 \%$ repolarization, and triangulation) within the normal range. The main ionic conductances considered were: fast and late $\mathrm{Na}^{+}$currents $\left(\mathrm{G}_{\mathrm{Na}}\right.$ and $\mathrm{G}_{\mathrm{NaL}}$, respectively), $\mathrm{I}_{\text {to }}\left(\mathrm{G}_{\mathrm{to}}\right), \mathrm{I}_{\mathrm{Kr}}$ and $\mathrm{I}_{\mathrm{Ks}}\left(\mathrm{G}_{\mathrm{Kr}}\right.$ and $\left.\mathrm{G}_{\mathrm{Ks}}\right)$, inward rectified $\mathrm{K}^{+}$current $\left(\mathrm{G}_{\mathrm{K} 1}\right), \mathrm{I}_{\mathrm{NCX}}$ $\left(\mathrm{G}_{\mathrm{NCX}}\right), \mathrm{Na}^{+} / \mathrm{K}^{+}$pump $\left(\mathrm{G}_{\mathrm{NaK}}\right)$, and $\mathrm{I}_{\mathrm{Ca}-\mathrm{L}}\left(\mathrm{G}_{\mathrm{Ca}-\mathrm{L}}\right)$. All simulations presented in this study were conducted using Virtual Assay (@) 2016, University of Oxford; v.1.3.640 2014; Oxford University Innovation Ltd.), a software package for in silico drug assays, kindly provided by B. Rodríguez.

In order to reproduce the hypothyroid phenotype in this population of 550 AP models, ionic conductances were modified according to the experimental findings in both a past study (10) and the present study. To simulate the change in $\mathrm{I}_{\mathrm{Ca}-\mathrm{L}}$ in both types of hypothyroidism, $\mathrm{G}_{\mathrm{Ca}-\mathrm{L}}$ was augmented by $55 \%$. To simulate the changes associated with primary hypothyroidism, $\mathrm{G}_{\text {to }}$ and $\mathrm{G}_{\mathrm{K} 1}$ were reduced to $50 \%$ of control, whereas $\mathrm{G}_{\mathrm{Ks}}$ and $\mathrm{G}_{\mathrm{NCX}}$ were reduced to $60 \%$ and $70 \%$ of control, respectively. In the simulations, trains of 500 AP were evoked at $1 \mathrm{~Hz}$, and the last AP trace in each simulation was presented.
Simulations of the impact of the ion current changes observed in hypothyroidism were also performed on the Nygren-Firek-Clark-Lindblad-Clark-Giles model (15) of human atrial AP. The simulations presented in this study were conducted with permission using The Virtual Heart Web page by Flavio Fenton (16-18), and are described in the Supplementary Methods.

\section{Statistical analysis}

Data are presented as means \pm standard error of the mean. Data were compared with Student's $t$-test or analysis of variance followed by Bonferroni's $t$-test. Arrhythmia incidence was evaluated with a contingency table and Pearson's chi-square test. A $p$-value of $<0.05$ was considered as statistically significant.

\section{Results}

\section{Animal models}

Although PTU treatment is a widely used procedure for induction of primary hypothyroidism, to the best of the authors' knowledge, an animal model of central hypothyroidism had not yet been developed. The anticancer drug BXT exerts a direct inhibitory effect on the TSH-producing cells of the pituitary gland $(19,20)$. Advantage was taken of this unwanted side effect to create a central hypothyroidism experimental model, which was tested in this study.

Both PTU and BXT treatments reduced blood T4 concentration within one week, attaining almost undetectable levels after two weeks (Fig. 1A). Since PTU directly induces malfunction of the thyroid gland, blood TSH concentration showed a 10-fold increase, reaching its maximum at week 4 . BXT, on
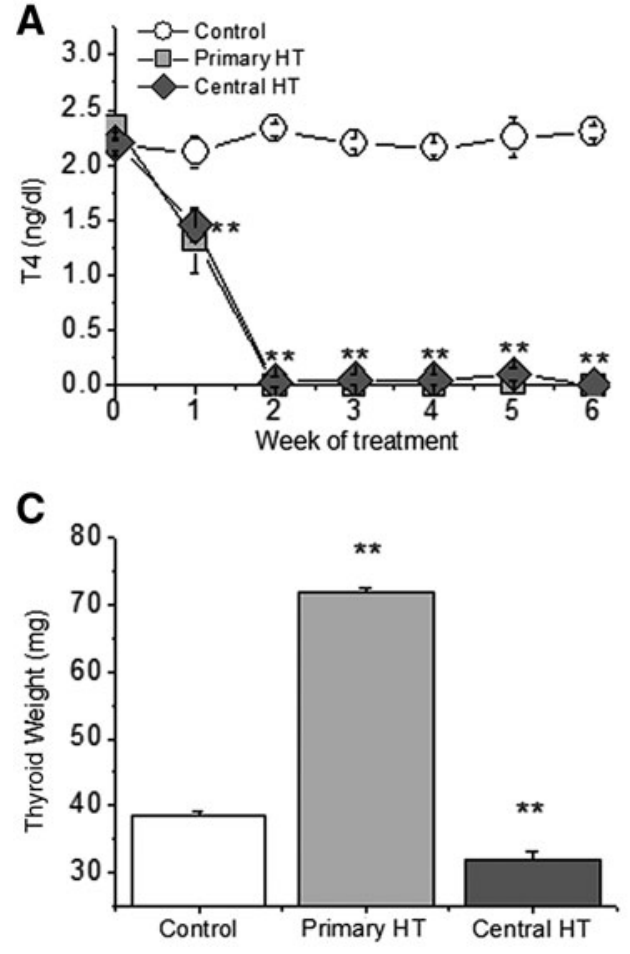
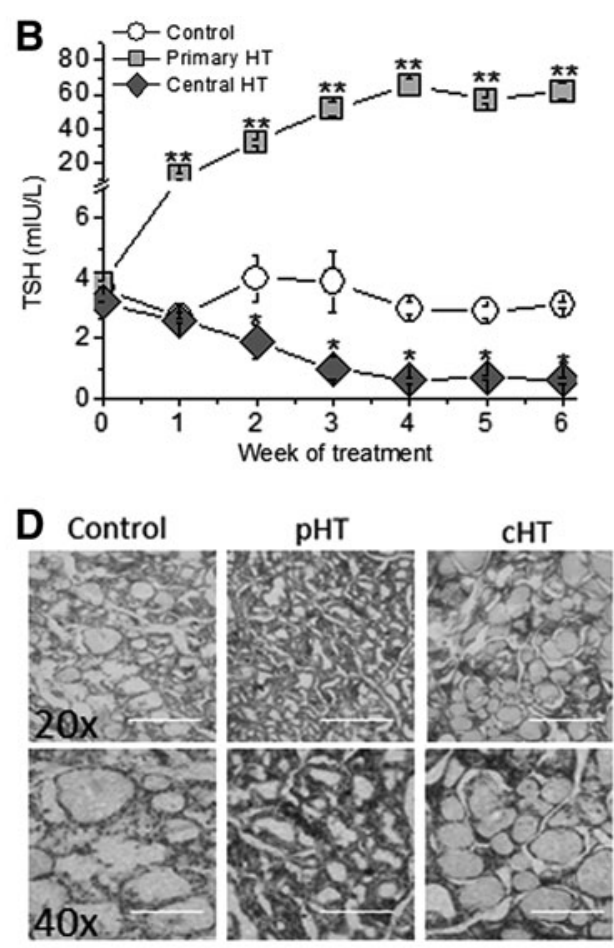

FIG. 1. Characterization of the hypothyroidism animal models. (A) Free thyroxine (T4) blood levels are almost undetectable after two weeks of either primary or central hypothyroidism. (B) Serum thyrotropin (TSH) levels were increased more than 10fold in primary hypothyroidism but were undetectable in animals with central hypothyroidism. (C) Thyroid gland weight showed opposite changes in primary and central hypothyroidism after six weeks of induction. (D) Hematoxylin and eosin stained sections of the thyroid gland six weeks after induction of primary (pHT) and central hypothyroidism (cHT) also show opposite structural modifications. Scale bars indicate $200 \mu \mathrm{m}$ and $100 \times \mu \mathrm{m}$ at $20 \times$ and $40 \times$, respectively. $n=18$ control, $15 \mathrm{pHT}$, and $17 \mathrm{cHT}$ animals. Means \pm standard error of the mean (SEM). $* p<0.05$; ** $p<0.01$. 
the other hand, is expected to reduce $\mathrm{T} 4$ levels due to its toxic effect on the pituitary gland. Accordingly, TSH levels were reduced, reaching the minimum at week 4 (Fig. 1B).

After six weeks of primary hypothyroidism, the high circulating TSH levels induced thyroid growth with an increase in epithelial cell height, whereas in low TSH central hypothyroidism, gland size and follicular cells height were slightly reduced (Fig. 1C and D and Supplementary Fig. 1A). Primary hypothyroidism reduced body weight, which was not changed in control or centrally hypothyroid animals. Neither body temperature nor relative heart mass was significantly different among the three groups of animals (Supplementary Fig. 1B-D).

\section{Electrocardiographic characteristics}

As previously published (21), primary hypothyroidism reduced heart rate compared to control animals, whereas a less pronounced effect was seen in the centrally hypothyroid group (Fig. 2A and B). Similarly to patients with primary hypothyroidism (5), the primary hypothyroidism group showed repolarization abnormalities, such as prolongation of the QT, QTc, and Tpeak-to-Tend intervals. However, none of these alterations was present in centrally hypothyroid animals (Fig. 2B).

The ECG alterations seen in hypothyroid animals may represent a substrate for the development of cardiac arrhythmias. Thus, the animals were subjected to an arrhythmia vulnerability test under acute challenge with caffeine and dobutamine. The incidence of cardiac arrhythmias was increased twofold in animals with primary hypothyroidism, while only a nonsignificant trend of increase was seen in the centrally hypothyroid group (Fig. 2C).

\section{Cardiac electrical remodeling}

The amplitude of $\mathrm{I}_{\mathrm{Ca}-\mathrm{L}}$ in ventricular myocytes increased in both primary and central hypothyroidism when compared to the control group (Fig. 3A and B). These results support the reported absence of effect of TSH on this current (10) and the suppressive effect of thyroid hormones on L-type $\mathrm{Ca}^{2+}$ channels, since T3/T4 deficiency increases both calcium channel expression and current amplitude $(22,23)$.

In ventricular myocytes isolated from animals with primary hypothyroidism, the $\mathrm{I}_{\text {to }}$ amplitude was reduced, but it was not affected by central hypothyroidism (Fig. 3C and D). In addition, hypothyroidism modified neither the voltagedependence of the steady-state inactivation of the current nor the time-dependence of recovery from inactivation (Supplementary Fig. 2A and B). Thus, although primary hypothyroidism reduced $\mathrm{I}_{\text {to }}$ density, the biophysical properties of the channel were not modified, suggesting a reduction of the channel abundance. Accordingly, expression of the Kv4.2 and $\mathrm{Kv} 4.3$ channel proteins was significantly reduced in ventricles from rats with primary hypothyroidism, but it was conserved in hypothyroidism of central origin (Supplementary Fig. 2C). Thus, the absence of thyroid hormones does not seem to be the mechanism responsible for the reduction in $\mathrm{I}_{\text {to }}$ density and channel expression in rats with primary hypothyroidism, pointing to high TSH levels as the likely factor involved in these changes.

Although its physiological relevance is lower than $\mathrm{I}_{\text {to }}$, the ultra-rapid delayed rectifier $\mathrm{K}^{+}$current $\mathrm{I}_{\mathrm{Kur}}$ is also present in the rat ventricle. In ventricular myocytes, the $\mathrm{I}_{\mathrm{Kur}}$ amplitude was similarly decreased in both primary and central hypothyroidism when compared to the control group (Supplementary Fig. 3A and B). As for $\mathrm{I}_{\mathrm{Ca}-\mathrm{L}}$, these results support a direct role of thyroid hormones and lack of influence of TSH on this current, as previously reported (10).

\section{Role of TSH in electrical remodeling}

Next, the study explored at the cellular level a possible direct role of TSH in the electrophysiological changes seen in animal models of hypothyroidism. Isolated ventricular myocytes were incubated for 24 hours in medium containing $30 \mathrm{mIU} / \mathrm{L}$ of TSH, a concentration commonly seen in primary hypothyroid patients. As shown in Figure 4A, TSH had no effect on $\mathrm{I}_{\mathrm{Ca}-\mathrm{L}}$ either in control or in the hypothyroid groups.

On the other hand, incubation with TSH differentially modulated the $\mathrm{I}_{\text {to }}$ amplitude in the three experimental groups. While exposure to TSH significantly reduced the $\mathrm{I}_{\text {to }}$ amplitude in myocytes from control and centrally hypothyroid rats (Fig. 4B), exogenous TSH had no effect on $\mathrm{I}_{\text {to }}$ density in myocytes from animals with primary hypothyroidism, a model with high circulating TSH levels in which $\mathrm{I}_{\text {to }}$ was already decreased (Fig. 4B).

\section{TSH effect on cardiomyocyte $\mathrm{Ca}^{2+}$ handling}

NCX has been implicated in the development of $\mathrm{Ca}^{2+}$ dependent spontaneous electrical activity in myocardial cells $(24,25)$. Incubation of control myocytes with TSH for 24 hours did not cause apparent cellular $\mathrm{Ca}^{2+}$ overload. However, TSH exposure significantly prolonged the decay phase of $\mathrm{Ca}^{2+}$ transients generated by caffeine-induced massive $\mathrm{SR} \mathrm{Ca}^{2+}$ release, which relies mainly on NCX (Fig. 5A, left). The decrease in the ratio of the time constants for decline of the cytosolic $\mathrm{Ca}^{2+}$ concentration of caffeine-evoked transients in the presence and absence of $\mathrm{Na}^{+}$after TSH incubation (Fig. 5A, right) confirmed that the hormone depressed the $\mathrm{Na}^{+}$-dependent $\mathrm{Ca}^{2+}$ efflux. Accordingly, the $\mathrm{I}_{\mathrm{NCX}}$ amplitude was smaller $(p<0.001)$ in cells preincubated with TSH, over the whole tested voltage range (Fig. 5B). Nevertheless, TSH treatment caused a leftward shift in the current reversal potential from $-17.4 \pm 4.9$ to $-46.5 \pm 6.4 \mathrm{mV}(p<0.01)$.

Finally, the effect of TSH incubation on the development of spontaneous contractions after interruption of electrical stimulation was tested in the absence and presence of the $\beta$-adrenoceptor agonist ISO. In the absence of the agonist, TSH-treated cells showed greater incidence of spontaneous activity after a brief (10 seconds) train of stimulation at all tested rates, from 0.5 to $2 \mathrm{~Hz}$ (Fig. 5C, left). Another stimulation protocol (1 Hz for 2 minutes) (26) was used to test $\beta$-adrenergic stimulation with ISO. Although ISO was effective at inducing automatism in cells incubated with and without TSH $(p<0.001)$, the response was more prominent in the latter group $(p<0.05$ for treatment $\times$ [ISO] interaction), in which the maximum rate of spontaneous events was twofold greater (Fig. 5C, right).

\section{Effects of TSH on human cardiac myocytes}

Next, the study explored whether the effects of TSH on cardiac electrical properties observed in rodents also occurred in human cardiomyocytes. Thus, the study tested whether TSH incubation for 24 hours affects the expression of the channels 

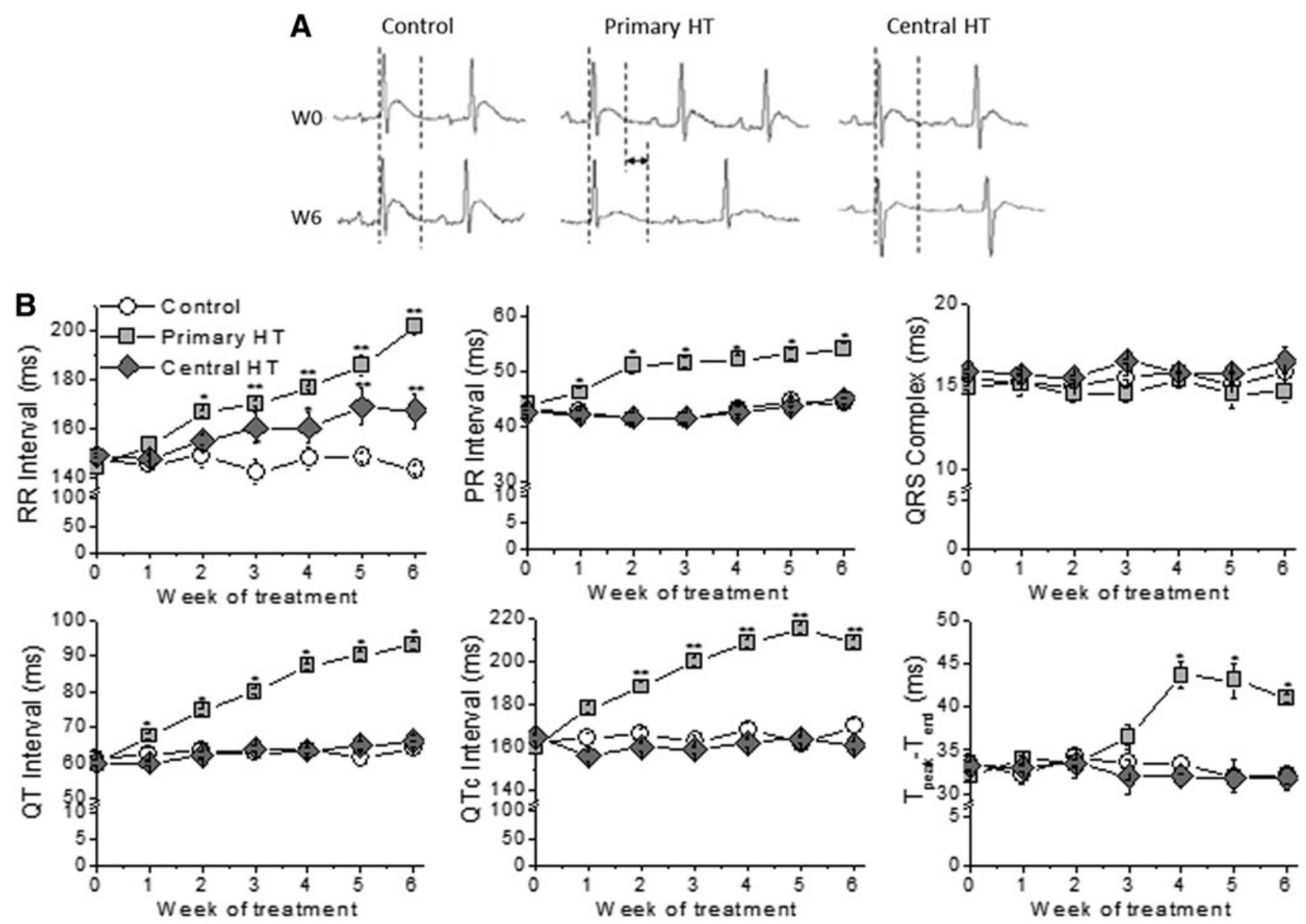

C Non Arrhythmic (Control)

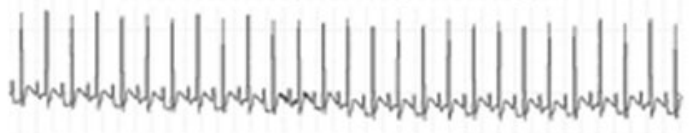

Arrhythmic (pHT)
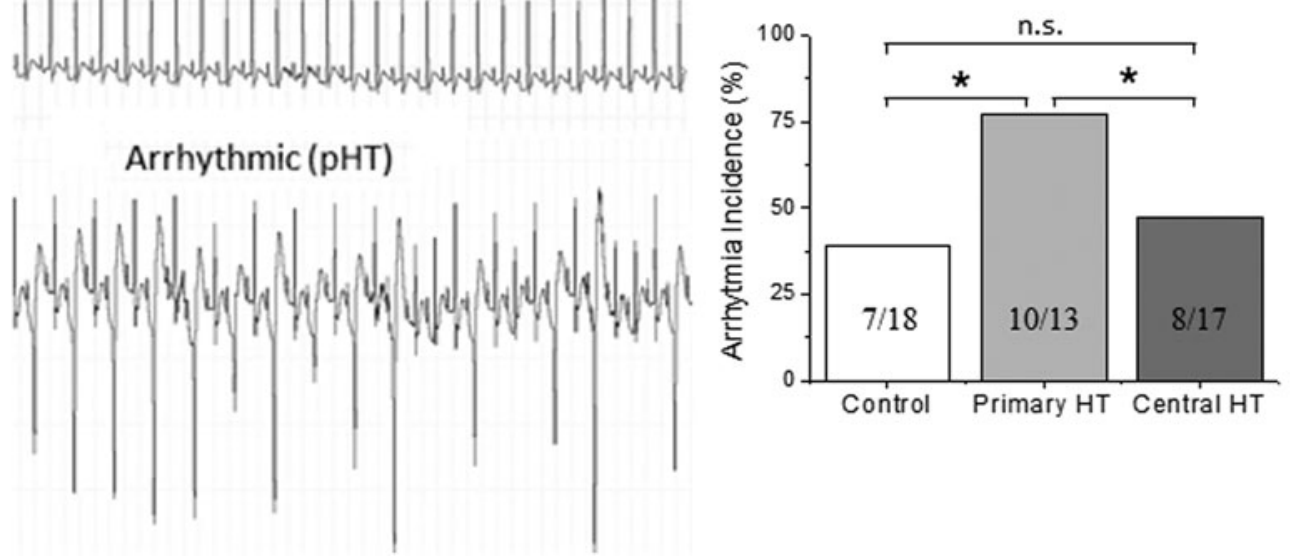

FIG. 2. Electrocardiographic (ECG) characteristics of central and primary hypothyroidism. (A) ECG recordings before (W0) and after six weeks of hypothyroidism (W6). The dotted lines delineate the QT interval. (B) Both central and primary HT prolonged the R-R interval. Only primary HT prolonged the QTc, PR and QT intervals, and Tpeak-to-Tend duration. QRS complex duration was not modified in any HT model $(n=18,13$, and 17 animals/group, respectively). (C) After caffeine/dobutamine challenge, the incidence of ventricular arrhythmias was increased twofold only in the primary hypothyroid group compared to control animals. The numbers in the columns are arrhythmic animals/total animals in the group. Data were compared with analysis of variance followed by Bonferroni's $t$-test. Means \pm SEM. $* p<0.05 ; * * p<0.01$. 
A

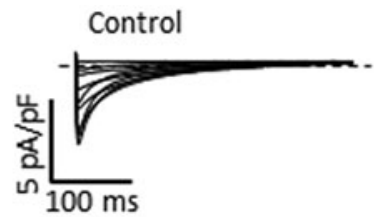

Primary HT

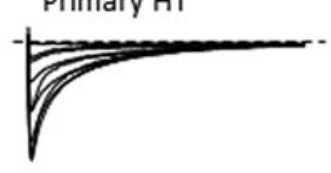

Central HT

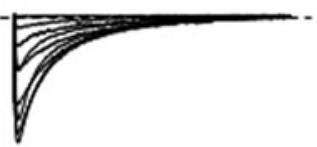

FIG. 3. Hypothyroidism differently modulated $\mathrm{Ca}^{2+}$ and $\mathrm{K}^{+}$currents. (A) $\mathrm{I}_{\mathrm{Ca}-\mathrm{L}}$ traces recorded in ventricular myocytes isolated from control animals and from animals with primary and central hypothyroidism. Dashed lines represent the 0 current level. (B) Current-voltage relationship and maximum $\mathrm{I}_{\mathrm{Ca}-\mathrm{L}}$ amplitude at $+10 \mathrm{mV}$ showing a similar increase in $\mathrm{I}_{\mathrm{Ca}-\mathrm{L}}$ density in both central and primary hypothyroidism $(n=8-15$ cells from at least three animals in each group; $* p<0.05)$. (C) Traces of $\mathrm{I}_{\mathrm{to}}$ recorded in ventricular myocytes isolated from control animals and from animals with primary and central hypothyroidism. Dashed lines represent the 0 current level. (D) Current-voltage relationships and maximum $\mathrm{I}_{\text {to }}$ amplitude at $+50 \mathrm{mV}$, showing that primary hypothyroidism reduced $\mathrm{I}_{\text {to }}$ density, whereas hypothyroidism of central origin had no effect on this current $(n=10-15$ cells from at least three animals in each group; $* p<0.05$ ).
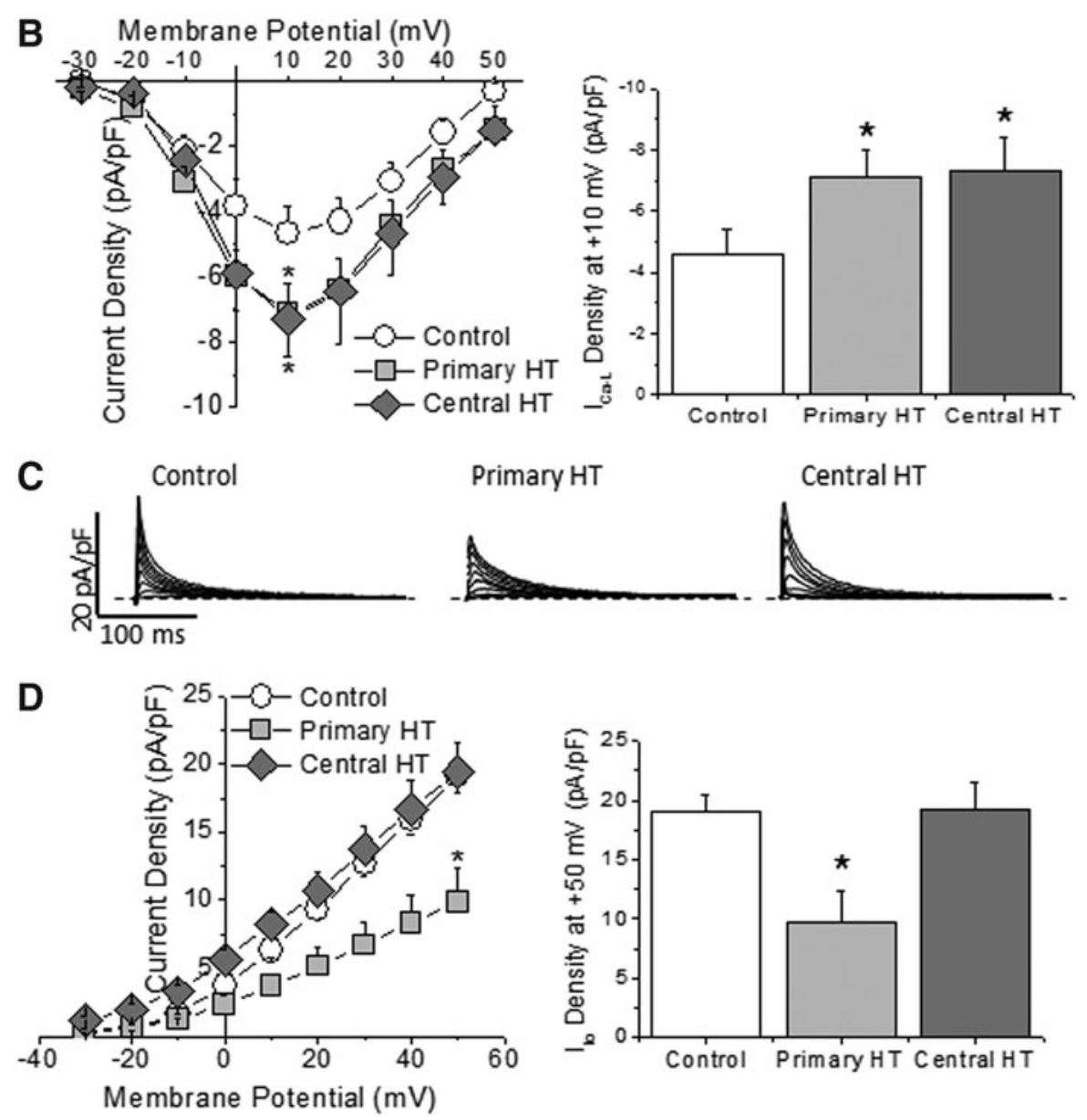

that carry repolarizing $\mathrm{K}^{+}$currents in adult human myocytes. TSH reduced the expression of the $K C N D 3$ and $K C N Q 1$ genes, which might result in a reduction of $\mathrm{I}_{\text {to }}$ and $\mathrm{I}_{\mathrm{Ks}}$, as seen in rodents in both prior studies $(10,22)$ and in the present study. $\mathrm{TSH}$, however, did not affect the expression of $\mathrm{KCNH} 2$, responsible for the $\mathrm{I}_{\mathrm{Kr}}$ current in human heart (Fig. 6A).

Next, the study explored the molecular mechanism involved in the effect of TSH on $\mathrm{K}^{+}$channel expression in the heart. The TSH receptor is canonically coupled to a Gs $\alpha$ protein and activates the adenylyl cyclase/PKA pathway. To test the effect of PKA inhibition, samples were treated with TSH for 24 hours in the presence of H89, which fully eliminated the effect of TSH on the expression of the studied channels (Fig. 6A).

\section{Computer simulation of human $A P$}

A population of 550 human ventricular AP profiles was simulated with different ion channel densities, by sampling the main ventricular ionic conductances in the 20-200\% range of the averaged values in the ORd model (13), either under resting conditions or after $\beta$-adrenergic stimulation (Fig. 6B). When ionic conductances were changed to simulate the alterations seen in the primary hypothyroid conditions (see Methods), 24/550 models showed EAD and arrhythmias under resting conditions, and the incidence increased to $33 / 550$ after $\beta$-adrenergic stimulation. When ionic conductances were adjusted to simulate central hypothyroidism, EAD was not observed under resting conditions, but after $\beta$-adrenergic stimulation, EADs and arrhythmias were generated in 26/550 cases.

The same kind of simulation carried out with the NygrenFirek-Clark-Lindblad-Clark-Giles model (15) of atrial AP reproduced the results obtained with the ventricular model: arrhythmias appeared in the primary hypothyroidism model, whereas only isolated EADs were seen in the central hypothyroidism model (Supplementary Fig. S4).

\section{Discussion}

For decades, PTU-induced hypothyroidism has been the most widely used animal model $(21,27)$. After PTU 
A
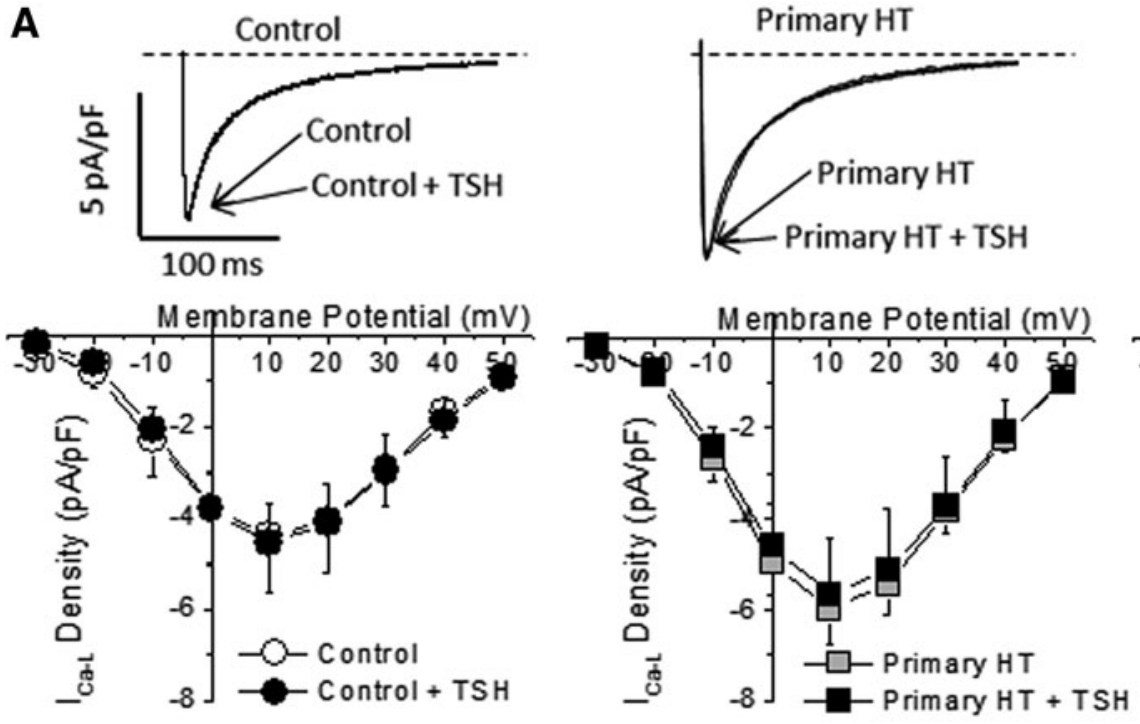

Primary HT
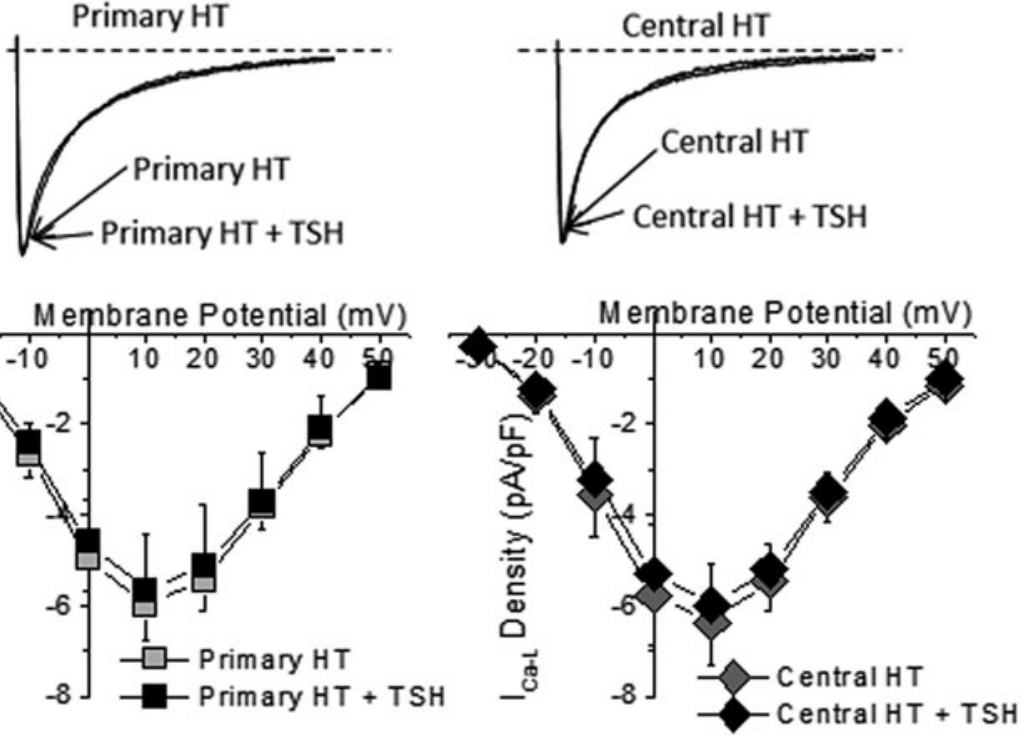

B
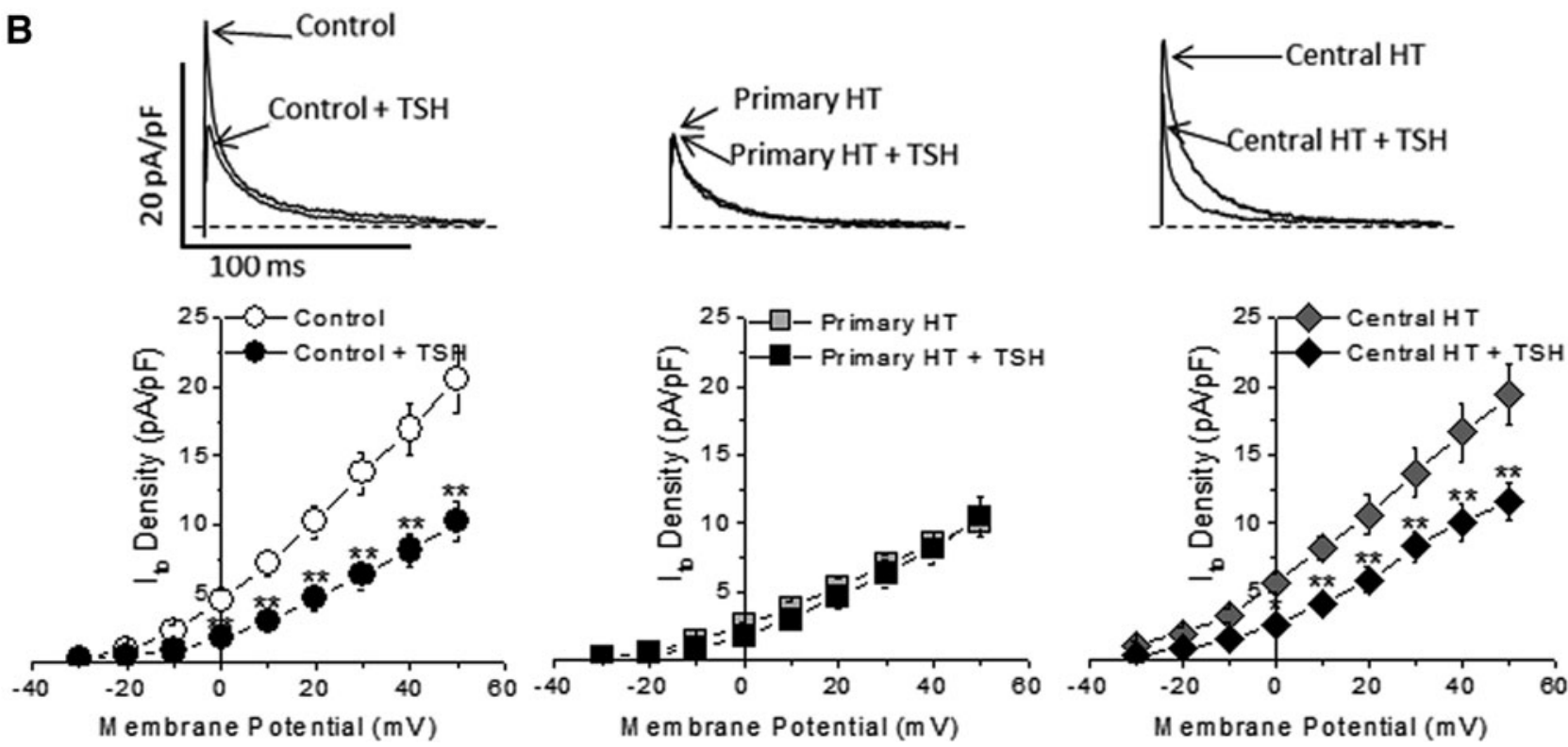

FIG. 4. TSH modulation of $\mathrm{Ca}^{2+}$ and $\mathrm{K}^{+}$currents in myocytes from control animals and rats with either central or primary hypothyroidism. (A) Incubation for 24 hours with $30 \mathrm{mIU} / \mathrm{L}$ of TSH did not affect $\mathrm{I}_{\mathrm{Ca}-\mathrm{L}}$ in any of the experimental groups ( $n=8-9$ cells from three different animals in each group). (B) Incubation with TSH reduced the $\mathrm{I}_{\text {to }}$ amplitude in the control and central hypothyroid groups, but had no effect in the primary hypothyroidism group. Means \pm SEM. $n=10-13$ cells from at least three different animals in each group. Dashed lines represent the 0 current level. $* p<0.05 ; * * p<0.01$.

treatment, T4 becomes undetectable, and TSH increases more than 10-fold. However, to the best of the authors' knowledge, a well-characterized animal model of central hypothyroidism has been lacking. The rexinoid drug BXT $(28,29)$ induces reversible central hypothyroidism in both patients and experimental animals $(19,20)$. In the present work, both T4 and TSH levels were very significantly reduced after BXT treatment, resulting in a sustained hypothyroid status. In conclusion, BXT treatment $(50 \mathrm{mg} / \mathrm{kg}$ by daily gavage) generates a new and reliable animal model of central hypothyroidism.

It is well known that secondary hypothyroidism does not produce the same clinical and biochemical degree of hypo- thyroidism as primary thyroid underfunction. In addition, secondary hypothyroidism is usually a part of a more complex phenotype, with anterior pituitary insufficiency or panhypopituitarism caused by entities such as pituitary/hypothalamic neoplasia or infiltration, surgery, or irradiation $(3,30)$. However, the severity of hypothyroidism found in the PTU and BXT animal models used in this study is similar, since T4 is undetectable in both. Many (probably most) cardiac and systemic manifestations of primary hypothyroidism are directly related to the lack of thyroid hormones. However, the novelty of the study presented here is to present data that demonstrate that a subset of the cardiac electrical remodeling is associated with the high TSH levels found in primary hypothyroidism. 
FIG. 5. Effects of in vitro TSH treatment on cardiomyocyte $\mathrm{Ca}^{2+}$ handling. (A) TSH increased the half-time $\left(\mathrm{t}_{0.5}\right)$ of $\left[\mathrm{Ca}^{2+}\right]_{\mathrm{i}}$ decay of caffeine-evoked transients, which depends mainly on NCX, and decreased the ratio of the rate constants of $\left[\mathrm{Ca}^{2+}\right]_{\mathrm{i}}$ decline of caffeine transients in the presence $\left(\mathrm{K}_{\text {caff }}\right)$ and absence of $\mathrm{Na}^{+}\left(\mathrm{K}_{\text {caff-ONa}}\right.$; $n=27$ in control and 29 in the TSH group). These results indicate a reduction of NCX activity in intact myocytes. (B) Recordings of the $\mathrm{I}_{\mathrm{NCX}}$ in isolated ventricular myocytes confirm the reduction of NCX activity by TSH $(n=8$ and 10 cells for control and TSH groups, respectively). (C) TSH increased the number of spontaneous contractions (SC) during 200 seconds after a 10 -second stimulation train at different frequencies $(n=18,22$, $16,18,11$, and 9 for each column, respectively). TSH treatment also enhanced the concentrationdependent induction of automatism by isoproterenol (ISO) in rat ventricular myocytes developed after interruption of electrical stimulation. $n=5$ cells in each group. Means \pm SEM. $* p<0.05$.
A
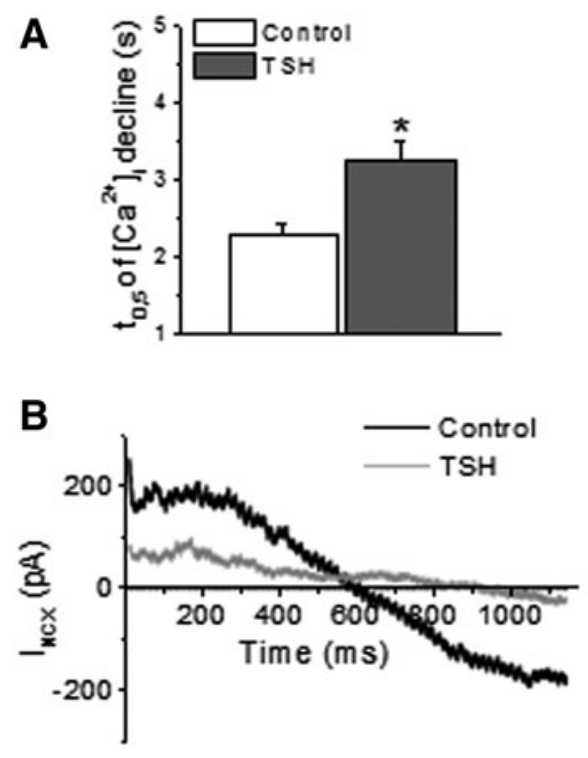

C

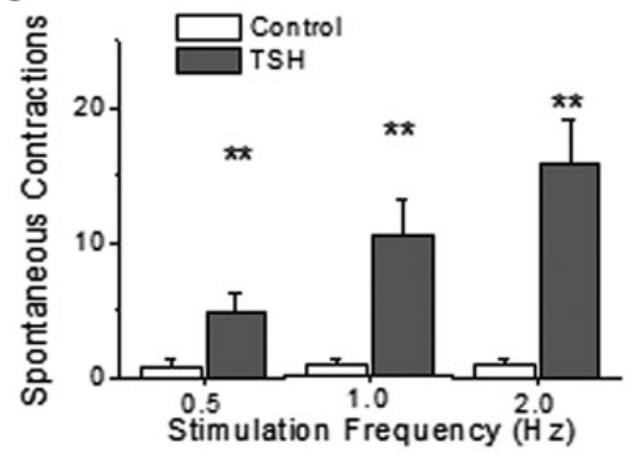

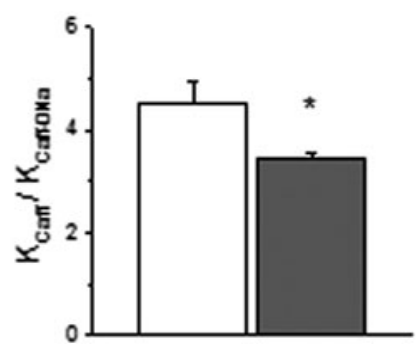
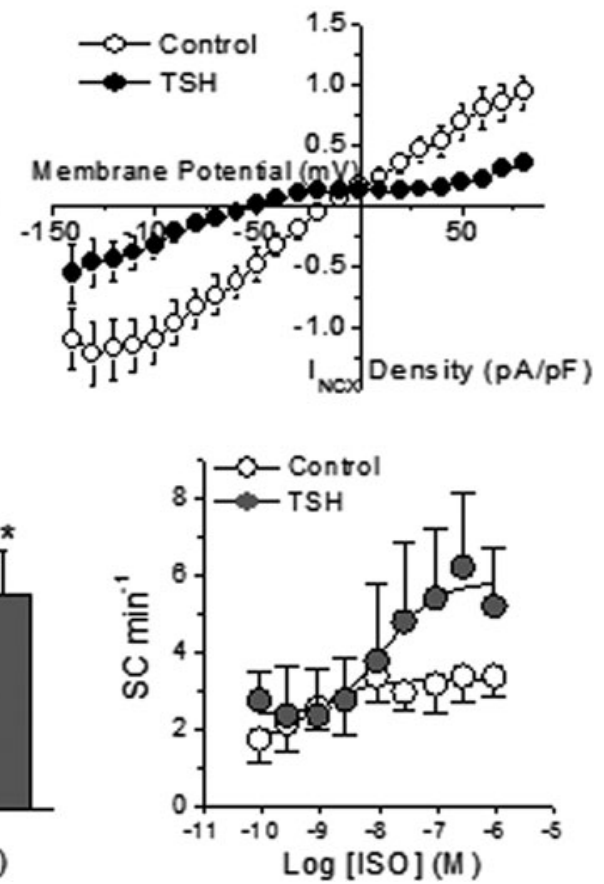

The prolongation of the QTc interval seen in ECGs of hypothyroid patients was reproduced in animals with primary hypothyroidism but not in the central hypothyroid model, which suggests that it is not solely dependent on thyroid hormone deficiency. In addition, the incidence of arrhythmias in rats with primary hypothyroidism was twofold elevated but not observed in animals with central hypothyroidism. Thus, we conclude that hypothyroidism-induced increase of the ventricular vulnerability to arrhythmia is associated with the high serum TSH levels.

Thyroid hormones inhibit the expression of L-type $\mathrm{Ca}^{2+}$ channels (23), and therefore, in primary hypothyroidism, CaCN1C gene expression increases (22). Accordingly, the present results show an increase of the $\mathrm{I}_{\mathrm{Ca}-\mathrm{L}}$ amplitude in the two models of hypothyroidism, supporting the causative role of the decreased levels of thyroid hormones. On the other hand, it was also observed that $\mathrm{I}_{\mathrm{Kur}}$ was reduced in both hypothyroid models, as in previous studies $(22,31)$. This indicates that both the $\mathrm{I}_{\mathrm{Ca}, \mathrm{L}}$ and the $\mathrm{I}_{\mathrm{Kur}}$ current are regulated by thyroid hormones but not by TSH, as previously reported (10). However, although the increase in $\mathrm{I}_{\mathrm{Ca}-\mathrm{L}}$ and the reduction in the $\mathrm{I}_{\mathrm{Kur}}$ amplitude should contribute to prolonged repolarization, this appears to occur only in primary but not in central hypothyroidism, suggesting that there must be other mechanisms involved in the ventricular electrical remodeling. Nevertheless, these changes might, at least in part, ex- plain the incidence of atrial arrhythmias in patients with hypothyroidism.

A classical trigger of arrhythmias is the depolarizing current carried by NCX, secondary to cellular $\mathrm{Ca}^{2+}$ overload (24-26). However, the current results indicate that this is not the trigger mechanism of the TSH-induced arrhythmogenesis. It was found that 24 hours of incubation of isolated cardiac myocytes with TSH did not cause $\mathrm{Ca}^{2+}$ overload and reduced the pro-arrhythmic $\mathrm{I}_{\mathrm{NCX}}$ current. Conversely, during $\beta$-adrenergic stimulation, the diastolic $\mathrm{Ca}^{2+}$ leak from the sarcoplasmic reticulum is enhanced due to greater $\mathrm{Ca}^{2+}$ accumulation in the organelle (with contribution of $\mathrm{I}_{\mathrm{Ca}-\mathrm{L}}$ stimulation, already augmented by hypothyroidism) and by indirect stimulation of $\mathrm{Ca}^{2+}$ releasing channels $(24,32)$. A greater $\mathrm{Ca}^{2+}$ leak is expected to enhance $\mathrm{I}_{\mathrm{NCX}}$ markedly because it increases the availability of subsarcolemmal $\mathrm{Ca}^{2+}$ to be transported by the NCX. This, added to the prolonged repolarization observed only after exposure to supranormal TSH levels (TSH incubation and primary hypothyroidism), is expected to promote pro-arrhythmic afterdepolarizations. It should be noted that in animals with both primary hypothyroidism and TSH-treated isolated myocytes, enhanced spontaneous/arrhythmic activity compared to controls was seen under $\beta$-adrenergic stimulation. Beta-adrenergic stimulation was also found to result in a marked increase in ventricular pro-arrhythmic events in primary hypothyroidism. 


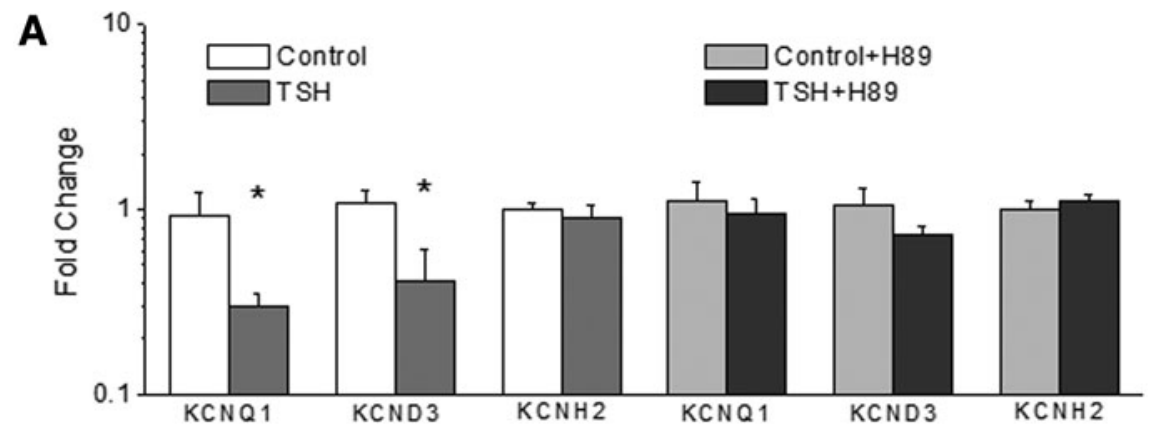

B
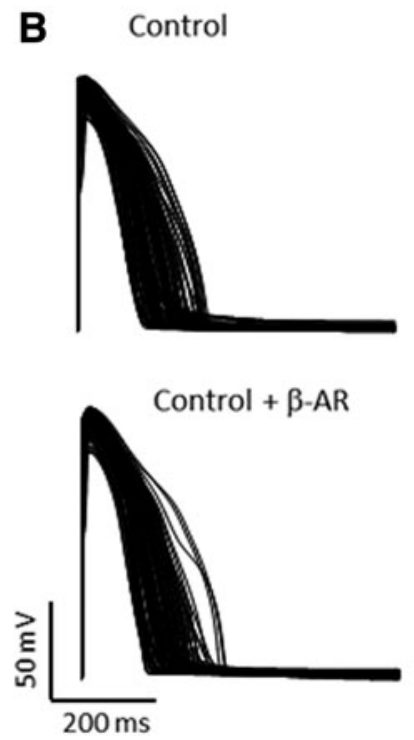

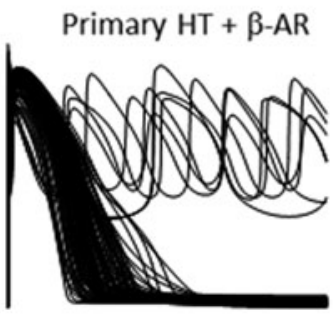

Primary HT

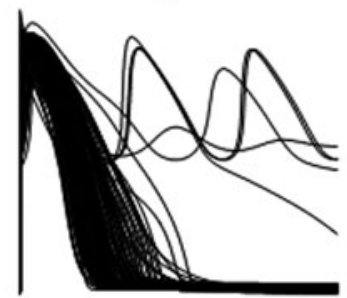

Central HT
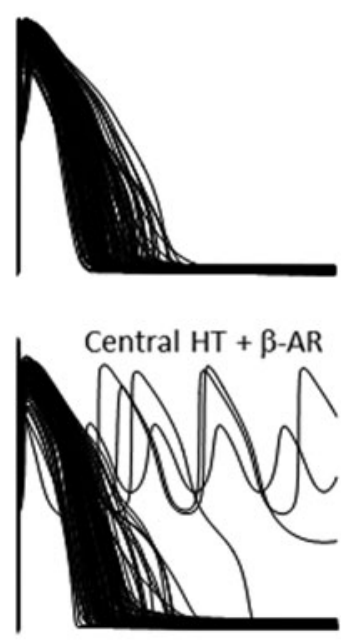

FIG. 6. Effects of TSH on human cardiac myocytes in vitro and in silico. (A) mRNA levels of $K C N Q 1$ and $K C N D 3$ were reduced in TSHtreated adult human atrial myocytes when compared to control myocytes, whereas $\mathrm{KCNH} 2$ expression was not affected. The effect of TSH was fully abolished by $5 \mu \mathrm{M}$ of the PKA blocker H89. $n=8$ hearts. Means \pm SEM. ${ }^{*} p<0.05$. (B) Computational models were generated to simulate the action potential of 550 control individuals in resting conditions (upper panel) and under $\beta$-adrenergic stimulation (lower panel). Only 110 randomly selected traces are shown for clarity. When the ionic conductances were changed to simulate the effects of primary hypothyroidism, early afterdepolarization (EAD) and arrhythmia appeared in resting conditions and increased after betaadrenergic stimulation. When ionic conductances were adjusted to simulate central hypothyroidism, EAD and arrhythmia were absent in resting conditions but present after $\beta$-adrenergic stimulation.
Overall, these findings indicate that that the electrical remodeling induced by TSH overexposure may sensitize the myocardium to the pro-arrhythmic influence of adrenergic stimulation, such as during exercise and under stressful conditions.

Although thyroid hormones are necessary for the $\mathrm{I}_{\text {to }}$ development in neonatal cardiac myocytes (33-35), it was consistently observed that thyroid hormones have no effect on $\mathrm{I}_{\text {to }}$ in cardiac myocytes from either euthyroid or hypothyroid adult animals $(35,36)$. Thus, while the increase in $\mathrm{I}_{\mathrm{Ca}-\mathrm{L}}$ in hypothyroid animals can be explained by the decrease in thyroid hormones, this does not apply to the decrease of $I_{t o}$. The present results suggest a direct action of $\mathrm{TSH}$ as the mechanism responsible for the $\mathrm{I}_{\text {to }}$ reduction. In accordance with this hypothesis and with previously published data $(10,21,22)$, ventricular $I_{\text {to }}$ was reduced in the high TSH model of primary hypothyroidism but not in the low TSH central hypothyroid model. In addition, the in vitro suppressive effect of TSH on $\mathrm{I}_{\text {to }}$ seen in myocytes from controls could not be reproduced in cardiomyocytes isolated from rats with primary hypothyroidism, in whom serum TSH levels were elevated for six weeks and $\mathrm{I}_{\text {to }}$ was already decreased. In contrast, incubation with TSH was able to reduce $I_{\text {to }}$ in cardiomyocytes from rats with central hypothyroidism, in whom TSH levels were not elevated and the $\mathrm{I}_{\text {to }}$ amplitude was not altered. All these results indicate a central role of TSH in the cellular electrical remodeling in primary hypothyroidism.
Although the prolongation of repolarization time seen in rodents is mainly associated with $\mathrm{I}_{\text {to }}$ inhibition, in humans, alterations of other $\mathrm{K}^{+}$currents cannot be excluded. Thus, the possible effects of TSH on human atrial samples were explored. TSH reduced the expression of the KCND3 and $K C N Q 1$ genes, which encode the channels that mediate $\mathrm{I}_{\text {to }}$ and $\mathrm{I}_{\mathrm{Ks}}$ respectively. This effect is likely to contribute to the prolonged repolarization reported in patients with primary hypothyroidism.

The presence of TSH receptors in the heart was previously reported both at the mRNA and protein levels, and these receptors appear to be functional and coupled to the adenylyl cyclase-PKA pathway $(37,38)$. The current and previously reported results (10) demonstrate that either TSH receptor blockade or PKA inhibition abolishes the effect of the hormone on cardiac $\mathrm{K}^{+}$channel expression, indicating that TSH acts through its canonical pathway in the heart.

To translate to the human heart the experimental data on susceptibility to triggered arrhythmia in hypothyroidism, computer simulations of the electrophysiological behavior of human cardiomyocytes were used. When the primary hypothyroid phenotype was introduced in the models, EADs and arrhythmias appeared, and their incidence increased after $\beta$-adrenergic stimulation, consistent with the higher incidence of arrhythmias in patients with primary hypothyroidism (5) and with the current in vivo and in vitro experimental results. It is also interesting to note that EADs and arrhythmias emerged only under $\beta$-adrenergic stimulation in the 
central hypothyroidism models. As pointed out, an increase in $\mathrm{I}_{\mathrm{Ca}-\mathrm{L}}$ reportedly due to thyroid hormone deficiency may contribute to EAD triggering during $\beta$-adrenergic stimulation in individuals with either type of hypothyroidism.

From a clinical perspective, several independent studies proposed that elevated serum TSH levels play an essential causal role in the QT prolongation and dispersion (QTd) in patients with overt hypothyroidism. These abnormalities revert after hormone replacement and normalization of TSH levels $(4,5,8)$. Here, based on the observations of the direct effect of TSH on the $\mathrm{K}^{+}$currents, a mechanistic explanation is proposed for the $\mathrm{TSH}$-dependent electrocardiographic alterations and its possible contribution to enhanced susceptibility to cardiac arrhythmias. These results, together with the recently published association between high normal TSH levels and increased risk of mortality, further contribute to answering the question of whether serum TSH reference ranges should be reexamined $(1,2,39,40)$.

\section{Acknowledgments}

This work was supported by Universidad del País Vasco UPV/EHU (PPG17/13), Ministerio de Economía y Competitividad MINECO (SAF2013-46708-R), and Gobierno Vasco (PIBA2018-58).

\section{Author Disclosure Statement}

No competing financial interests exist.

\section{Supplementary Material}

Supplementary Methods

Supplementary Table S1

Supplementary Table S2

Supplementary Figure S1

Supplementary Figure S2

Supplementary Figure S3

Supplementary Figure S4

\section{References}

1. Akirov A, Gimbel H, Grossman A, Shochat T, Shimon I 2017 Elevated TSH in adults treated for hypothyroidism is associated with increased mortality. Eur J Endocrinol 176: 57-66.

2. Inoue K, Tsujimoto T, Saito J, Sugiyama T 2016 Association between serum thyrotropin levels and mortality among euthyroid adults in the United States. Thyroid 10:1457-1465.

3. Roberts CG, Ladenson PW 2004 Hypothyroidism. Lancet 363:793-803.

4. Unal O, Erturk E, Ozkan H, Kiyici S, Guclu M, Ersoy C, Yener F, Imamoglu S 2007 Effect of levothyroxine treatment on QT dispersion in patients with subclinical hypothyroidism. Endocr Pract 13:711-715.

5. Galetta F, Franzoni F, Fallahi P, Tocchini L, Braccini L, Santoro G, Antonelli A 2008 Changes in heart rate variability and QT dispersion in patients with overt hypothyroidism. Eur J Endocrinol 158:85-90.

6. Task Force of the European Society of Cardiology and the North American Society of Pacing and Electrophysiology 1996 Heart rate variability. Standards of measurement, physiological interpretation, and clinical use. Circulation 93:1043-1065.
7. Galetta F, Franzoni F, Fallahi P, Tocchini L, Merico G, Braccini L, Rossi M, Carpi A, Antonelli A, Santoro G 2006 Heart rate variability and QT dispersion in patients with subclinical hypothyroidism. Biomed Pharmacother 60:431-436.

8. Bakiner O, Ertorer M, Haydardedeoglu F, Bozkirli E, Tutuncu N, Demirag N 2008 Subclinical hypothyroidism is characterized by increased QT interval dispersion among women. Med Princ Pract 17:390-394.

9. Akın A, Unal E, Yıldırım R, Ture M, Balık H, Haspolat YK 2018 Evaluation of QT dispersion and Tp-e interval in children with subclinical hypothyroidism. Pacing Clin Electrophysiol 41:372-375.

10. Alonso H, Fernández-Ruocco J, Gallego M, MalaguetaVieira LL, Rodríguez-de-Yurre A, Medei E, Casis O 2015 Thyroid stimulating hormone directly modulates cardiac electrical activity. J Mol Cel Cardiol 89:280-286.

11. Monnerat G, Alarcón ML, Vasconcellos LR, HochmanMendez C, Brasil G, Bassani RA, Casis O, Malan D, Travassos LH, Sepúlveda M, Burgos JI, Vila-Petroff M, Dutra FF, Bozza MT, Paiva CN, Carvalho AB , Bonomo A, Fleischmann BK, Campos de Carvalho AC, Medei E 2016 Macrophage-dependent IL-1b production induces cardiac arrhythmias in diabetic mice. Nat Commun 7:13344.

12. Bassani RA, Ricardo RA, Bassani JW 2012 Estimation of the fractional sarcoplasmic reticulum $\mathrm{Ca}^{2+}$ release in intact cardiomyocytes using integrated $\mathrm{Ca}^{2+}$ fluxes. Gen Physiol Biophys 31:401-408.

13. O'Hara T, Virág L, Varró A, Rudy Y 2011 Simulation of the undiseased human cardiac ventricular action potential: Model formulation and experimental validation. PLoS Comput Biol 7:e1002061.

14. Passini E, Britton OJ, Lu HR, Rohrbacher J, Hermans AN, Gallacher DJ, Greig RJH, Bueno-Orovio A, Rodriguez B 2017 Human in silico drug trials demonstrate higher accuracy than animal models in predicting clinical proarrhythmic cardiotoxicity. Front Physiol 8:668.

15. Nygren A, Fiset C, Firek L, Clark JW, Lindblad DS, Clark RB, Giles WR 1998 Mathematical model of an adult human atrial cell: the role of $\mathrm{K}^{+}$currents in repolarization. Circ Res 82:63-81.

16. Fenton F, Cherry E. The Virtual Heart. Available at: http:// dev1.thevirtualheart.org/ (accessed January 16, 2019).

17. Fenton FH, Cherry EM 2008 Models of cardiac cell. Scholarpedia 3:1868.

18. Fenton FH, Cherry EM, Hastings HM, Evans SJ 2002 Realtime computer simulations of excitable media: JAVA as a scientific language and as a wrapper for $\mathrm{C}$ and FORTRAN programs. Biosystems 64:73-96.

19. Golden WM, Weber KB, Hernandez TL, Sherman SI, Woodmansee WW, Haugen BR 2007 Single-dose rexinoid rapidly and specifically suppresses serum thyrotropin in normal subjects. J Clin Endocrinol Metab 92:124-130.

20. Liu S, Ogilvie KM, Klausing K, Lawson MA, Jolley D, Li D, Bilakovics J, Pascual B, Hein N, Urcan M, Leibowitz MD 2002 Mechanism of selective retinoid X receptor agonist-induced hypothyroidism in the rat. Endocrinology 143:2880-2885.

21. Ferrer T, Arín RM, Casis E, Torres-Jacome J, SanchezChapula JA, Casis O 2012 Mechanisms responsible for the altered cardiac repolarization dispersion in experimental hypothyroidism. Acta Physiol (Oxf) 204:502-512.

22. Le Bouter S, Demolombe S, Chambellan A, Bellocq C, Aimond F, Toumaniantz G, Lande G, Siavoshian S, Baró I, Pond AL, Nerbonne JM, Léger JJ, Escande D, Charpentier 
F 2003 Microarray analysis reveals complex remodeling of cardiac ion channel expression with altered thyroid status: relation to cellular and integrated electrophysiology. Circ Res 92:234-242.

23. Watanabe H, Washizuka T, Komura S, Yoshida T, Hosaka Y, Hatada K, Aizawa Y, Chinushi M, Yamamoto T, Ma M, Watanabe K 2005 Genomic and non-genomic regulation of L-type calcium channels in rat ventricle by thyroid hormone. Endocr Res 31:59-70.

24. Ter Keurs HE, Boyden PA 2007 Calcium and arrhythmogenesis. Physiol Rev 87:457-506.

25. Bassani RA, Bassani JWM, Lipsius SL, Bers DM 1997 Diastolic SR Ca efflux in atrial pacemaker cells and Caoverloaded myocytes. Am J Physiol Heart Circ Physiol 273:H886-882.

26. Boer D, Bassani JWM, Bassani RA 2011 Functional antagonism of $\beta$-adrenoceptor subtypes in the catecholamineinduced automatism in rat myocardium. Br $\mathrm{J}$ Pharmacol 162:1314-1325.

27. Rosai J 1996 Thyroid gland. In: Underdown ED (ed). Endocrine Physiology. Mosby-Year Book, Inc., St. Louis, MO, pp 493-513.

28. Haugen BR, Larson LL, Pugazhenthi U, Hays WR, Klopper JP, Kramer CA, Sharma V 2004 Retinoic acid and retinoid X receptors are differentially expressed in thyroid cancer and thyroid carcinoma cell lines and predict response to treatment with retinoids. J Clin Endocrinol Metab 89:272-280.

29. Klopper JP, Hays WR, Sharma V, Baumbusch MA, Hershman JM, Haugen BR 2004 Retinoid X receptorgamma and peroxisome proliferator-activated receptorgamma expression predicts thyroid carcinoma cell response to retinoid and thiazolidinedione treatment. Mol Cancer Ther 3:1011-1020.

30. Machado C, Oliveira D, Magalhaes M, Carvalho E, Ramalho F 1994 J Neural Transm Gen 97:149-59.

31. Ojamaa K, Kenessey A, Shenoy R, Klein I 2000 Thyroid hormone metabolism and cardiac gene expression after acute myocardial infarction in the rat. Am J Physiol Endocrinol Metab 279:E1319-1324.

32. Pereira L, Bare DJ, Galice S, Shannon TR, Bers DM 2017 $\beta$-Adrenergic induced SR $\mathrm{Ca}^{2+}$ leak is mediated by an Epac-NOS pathway. J Mol Cell Cardiol 108:8-16.
33. Wickenden AD, Kaprielian R, Parker TG, Jones OT, Backx PH 1997 Effects of development and thyroid hormone on $\mathrm{K}^{+}$currents and $\mathrm{K}^{+}$channel gene expression in rat ventricle. J Physiol 504:271-286.

34. Shimoni Y, Severson D, Giles W 1995 Thyroid status and diabetes modulate regional differences in potassium currents in rat ventricle. J Physiol 488:673-688.

35. Shimoni Y, Fiset C, Clark RB, Dixon JE, McKinnon D, Giles W 1997 Thyroid hormone regulates postnatal expression of transient $\mathrm{K}^{+}$channel isoforms in rat ventricle. $\mathrm{J}$ Physiol 500:65-73.

36. Sun ZQ, Ojamaa K, Coetzee WA, Artman M, Klein I 2000 Effects of thyroid hormone on action potential and repolarizing currents in rat ventricular myocytes. Am J Physiol Endocrinol Metab 278:E302-E307.

37. Davies T, Marians R, Latif R 2002 The TSH receptor reveals itself. J Clin Invest 110:161-164.

38. Huang W, Xu J, Jing F, Chen WB, Gao L, Yuan HT, Zhao JJ 2014 Functional thyrotropin receptor expression in the ventricle and the effects on ventricular BNP secretion. Endocrine 46:328-339.

39. Leung AM 2016 Mortality risks among individuals with high-normal serum TSH concentrations were increased as compared with those with midnormal TSH concentrations. Clin Thyroidol 28:287-289.

40. Spaulding SW 2017 Sequential TSH determinations may help in assessing the adequacy of treatment for overt hypothyroidism in older patients. Clin Thyroidol 29:48-51.

Address correspondence to: Oscar Casis, $M D, P h D$ Departamento de Fisiología Facultad de Farmacia Universidad del País Vasco Paseo de la Universidad 7 01006 Vitoria-Gasteiz Spain

E-mail: oscar.casis@ehu.eus 